\title{
Pemberdayaan Anggota Aisyiyah Cabang Kasihan Berbasis Olahan Bahan Pangan Lokal
}

\author{
Eni Istiyanti*1, dan Sarjiyah ${ }^{2}$ \\ 1. Program Studi Agribisnis, Fakultas Pertanian, Universitas Muhammadiyah Yogyakarta \\ 2. Program Studi Agroteknologi, Fakultas Pertanian, Universitas Muhammadiyah Yogyakarta \\ Email: eniistiyanti@umy.ac.id \\ DOI: $10.18196 /$ ppm.34.304
}

\begin{abstract}
Abstrak
Anggota Aisyiyah Ranting Ngestiharjo dan Tamantirto Utara cabang Kasihan mempunyai usaha produksi snack (jajanan) dengan bahan baku sebagian besar dari tepung terigu. Snack yang diproduksi dengan bahan pangan lokal seperti ubi jalar dan ubi kayu masih sangat terbatas dengan tampilan yang kurang menarik konsumen kekinian. Hal ini disebabkan karena pengetahuan dan ketrampilan dalam mengolah bahan pangan lokal masih terbatas. Tujuan dari kajian ini yaitu 1) meningkatkan pengetahuan dan ketrampilan membuat jajanan (snack) berbasis bahan pangan lokal, 2) mengembangkan strategi pemasaran yang sesuai agar snack dari bahan pangan lokal dikenal dan diminati banyak konsumen. Guna mengatasi permasalahan tersebut diperlukan pelatihan pembuatan snack dari bahan pangan lokal (ubi jalar dan tepung mocaf) dan fasilitasi peralatan serta penyuluhan dan pendampingan dalam menerapkan strategi pemasaran. Hasil kajian menunjukkan bahwa adanya pelatihan dan fisilitasi peralatan dapat meningkatkan ketrampilan dalam mengolah bahan pangan lokal dari ubi jalar dan tepung mocaf menjadi berbagai kue dan roti. Penerapan strategi pemasaran yang tepat dapat meningkatkan permintaan konsumen. Konsumen menjadi bertambah karena tampilan snack menarik, rasanya enak dan harganya tidak mahal.
\end{abstract}

Kata Kunci: 'Aisyiyah, mocaf, pangan lokal, pemberdayaan

\section{Pendahuluan}

Pangan lokal adalah pangan yang diproduksi dan dikembangkan sesuai dengan potensi dan sumberdaya wilayah dan budaya setempat. Oleh karenanya jenis, jumlah dan kualitas produk pangan lokal akan sangat tergantung pada kondisi spesifik yang ada pada wilayah tersebut. Kondisi ini bukan hanya pada kesesuaian lahan, sifat tanah, iklim dan aspek budidaya yang mempengaruhi, tetapi juga kondisi sosial ekonomi dan budaya masyarakat wilayah tersebut. Beragam pangan lokal tersebar di wilayah Indonesia, misalnya jagung, garut, ganyong, gembili, gadung, uwi, ubi jalar dan singkong (Direktorat Gizi Departemen Kesehatan RI, dalam Utami \& Budiningsih, 2015). Tiap daerah di Indonesia mempunyai potensi bahan pangan lokal yang berbeda dan pada umumnya belum dapat dikembangkan secara optimal.

Kabupaten Bantul merupakan salah satu kabupaten di Daerah Istimewa Yogyakarta yang mempunyai luas wilayah sebesar 50.194 ha yang terdiri dari 30\% lahan sawah, 25\% lahan pertanian bukan sawah dan $45 \%$ lahan bukan pertanian. Produksi tanaman pangan di Kabupaten Bantul pada tahun 2016 meliputi padi 183.211 ton, jagung 25.394 ton, ubi kayu 27.962 ton, ubi jalar 425 ton, kacang tanah 3.448 ton dan kedelai 1.262 ton (Badan Pusat Statistik, 2017).

Sebagian besar pengusaha makanan kecil (snack) termasuk di Kecamatan Kasihan menggunakan bahan baku tepung terigu. Tepung terigu berasal dari biji gandum yang di Indonesia belum dapat memproduksi sendiri sehingga harus mengimpor dari berbagai negara. Impor gandum Indonesia meningkat dari tahun ke tahun dengan pertumbuhan sekitar 5\% per tahun (Hastuti,2016). Guna menekan pertumbuhan impor gandum, perlu adanya upaya mensubstitusikan tepung terigu dengan tepung yang berasal dari bahan pangan lokal. Salah satu tepung yang mempunyai karakteristik yang menyerupai tepung terigu adalah tepung mocaf. Tepung mocaf dibuat melalui proses fermentasi yang mempunyai tekstur lebih halus, 
lebih mekar pada produk olahannya dan tidak berbau ubikayu (Subagiyo, et al. 2011). Selain dari tepung, bahan pangan lokal berupa ubi-ubian seperti ubi jalar juga dapat diolah menjadi makanan kecil (snack) berupa kue atau roti yang rasanya tidak kalah enaknya dengan kue dari tepung terigu (Ginting et al, 2011). Pada kenyataannya snack dari bahan pangan lokal dihasilkan oleh pengusaha di Cabang Kasihan masih terbatas jenisny, antara lain timus, lemet, arem-arem, lemper dan nagasari. Snack semacam ini kurang diminati oleh konsumen anakanak muda (konsumen kekinian).

Tujuan dari kajian ini adalah 1) meningkatkan pengetahuan dan ketrampilan pengusaha makanan kecil (snack) berbahan pangan lokal 2) mengembangkan strategi pemasaran makanan kecil (snack) yang tepat.

\section{Metode Pelaksanaan}

Pemberdayaan anggota Aisyiyah Cabang Kasihan berbasis olahan bahan pangan lokal dilakukan melalui berbagai kegiatan yaitu:

1. Peningkatan pengetahuan dan ketrampilan pengusaha snack di Ranting Tamantirto Utara dan Ngestiharjo dilakukan dengan pelatihan dan praktik serta fasilitasi peralatan membuat kue dan roti dari bahan tepung mocaf dan ubi jalar menjadi. Kegiatan selanjutnya adalah monitoring terhadap produksi kue dengan bahan pangan lokal. Adanya pelatihan dan fasilitasi peralatan, diharapkan ibu-ibu anggota Aisyiyah mampu membuat kue atau roti dari ubi jalar atau tepung mocaf berupa brownies, cookies, risoles mayones, donat dan pizza.

2. Snack dengan bahan baku pangan lokal masih dinilai kualitasnya lebih rendah dibandingkan makanan dari tepung terigu, oleh karena itu perlu dikembangkan strategi pemasaran yang tepat, melalui kegiatan:

a. Penyuluhan dan diskusi tentang berbagai strategi pemasaran makanan ringan (snack). Partisipasi peserta dalam penyuluhan sangat penting, karena selama ini pemasaran yang dilakukan hanya di sekitar Desa Tamantirto dan Ngestiharjo

b. Pendampingan dalam menjalin kerjasama dengan organisasi otonom Muhammadiyah di Kabupaten Bantul meliputi Muhammadiyah, Aisyiyah Nasyiatul Aisyiyah dan Pemuda Muhammadiyah tingkat Daerah dan Cabang. Kerjasama dapat dalam bentuk, apabila akan mengadakan suatu kegiatan, konsumsi diorder ke Aisyiyah Ranting Tamantirto Utara dan Ngestiharjo. Adanya kerjasama dapat memperluas jaringan pemasaran snack dengan bahan baku pangan lokal.

c. Pendampingan dalam melakukan promosi secara on line menggunakan media sosial. Pada era teknologi informasi seperti sekarang, aktivitas secara on line lebih diminati masyarakat dibandingkan off line. Adanya pendampingan dalam pemasaran secara on line, mempermudah anggota Aisyiyah Ranting Tamantirto Utara dan Ngestiharjo untuk memasarkan snack dari bahan pangan lokal secara on line sehingga pangsa pasarnya semakin luas.

2. Monitoring dan Evaluasi Kegiatan

a. Evaluasi sebelum pelaksanaan kegiatan

Indikator yang digunakan meliputi kesanggupan dan kemampuan anggota Aisyiyah Ranting Tamantirto Utara dan Ngestiharjo untuk mengikuti kegiatan yang akan dilakukan. Sebelum dilakukan kegiatan pelatihan pembuatan kue dari bahan pangan lokal, penyuluhan manajemen usaha dan strategi pemasaran perlu dilakukan pre test untuk mengetahui seberapa tingkat pengetahuan peserta terhadap berbagai hal yang terkait materi.

b. Evaluasi selama kegiatan berlangsung 
Indikator yang digunakan meliputi pemahaman anggota Aisyiyah Ranting Tamantirto Utara dan Ngestiharjo terhadap materi kegiatan, kemauan dan motivasi untuk mengimplementasikannya agar mencapai hasil yang maksimal. Peserta yang selalu hadir mengikuti kegiatan penyuluhan, pelatihan dan pendampingan pembuatan kue/roti dari bahan pangan lokal, manajemen usaha dan strategi pemasaran mendapatkan skor yang bagus.

c. Evaluasi setelah kegiatan selesai

Setelah pelaksanaan kegiatan juga dilakukan post test untuk mengetahui apakah ada tambahan pengetahuan dan pemahaman dalam pengolahan bahan pangan lokal, manajemen usaha dan strategi pemasaran. Indikator lain yang digunakan pada evaluasi setelah kegiatan meliputi minat dan kemampuannya untuk dapat melanjutkan hasil transfer teknologi tepat guna, pelatihan dan pendampingan yang telah dilakukan. Apakah anggota kelompok Aisyiyah Ranting Tamantirto Utara dan Ngestiharjo secara kontinyu melakukan proses produksi snack dari bahan pangan lokal dengan kualitas yang baik, melakukan pengelolaan usaha dan menerapkan trategi pemasaran yang tepat.

\section{Hasil dan Pembahasan}

\section{Pelatihan dan praktik pembuatan kue dan roti}

Pelatihan dan praktik pembuatan roti/kue dilakukan di tiap mitra. Praktik pembuatan roti di Aisyiyah Ranting Tamantirto Utara dilaksanakan dua kali yaitu pada hari Minggu 15 Maret 2020 jam 13.00-16.00 dan Sabtu 25 Juli 2020 jam 13.00 - 16.30 di rumah salah satu pengurus dan diikuti oleh 12 orang. Praktik pertama yaitu pembuatan kue/roti dengan bahan tepung mocaf. Ada 3 kue dari tepung mocaf yang dilatih yaitu brownies, cookies dan risoles mayones. Pelatihan kedua menggunakan bahan ubi jalar menjadi brownies, donat dan pizza. Setelah dijelaskan cara pembuatannya oleh trainer, ibu-ibu peserta pelatihan langsung praktik didampingi tim abdimas. Ibu-ibu mencoba semua tahapan dalam pembuatan kue mulai dari mencampur bahan-bahan, mengaduk, mencetak, memanggang, mengukus serta menggoreng secara bergantian. Hal ini sesuai dengan yang dilakukan oleh Bakti, et al (2017) dengan metode ceramah, diskusi dan praktek dapat meningkatkan keterampilan mengolah hasil ubi menjadi makanan yang variatif, bergizi, dan mempunyai cita rasa yang enak.

Pembuatan kue dari tepung mocaf pada dasarnya tidak berbeda dengan pembuatan kue dari tepung terigu. Tepung mocaf, gula, telur dan bahan-bahan lain dilembutkan menggunakan mixer kemudian dikukus untuk membuat brownies atau dipanggang untuk membuat cookies. Pada pembuatan risoles mayones, tepung mocaf dipakai untuk membuat kulitnya. Adonan untuk membuat kulit risoles lebih cair agar kulit yang dibuat tidak tebal. Kulit risoles diisi dengan sosis, bawang bombai dan mayones, kemudian dibentuk dan digoreng.

Bahan baku ubi jalar untuk membuat kue, harus dikukus terlebih dahulu. Ubi jalar yang sudah lunak (matang), kulit dihilangkan kemudian dilembutkan menggunakan tangan. Setelah ubi jalar lembut, dicampur bahan-bahan lain sesuai dengan peruntukannya. Pada pembuatan brownies, ubi jalar dan bahan-bahan lain diaduk menggunakan mixer, sedangkan untuk pizza dan donat tidak perlu. Adonan untuk pizza yang sudah siap, dicetak dalam loyang, diberi toping sesuai selera,kemudian dipanggang, sedangkan adonan untuk brownies setelah dicetak terus dikukus sampai matang. Pembuatan donat ubi jalar tidak berbeda dengan donat dari bahan lain, setelah adonan siap, dicetak, kemudian digoreng. 


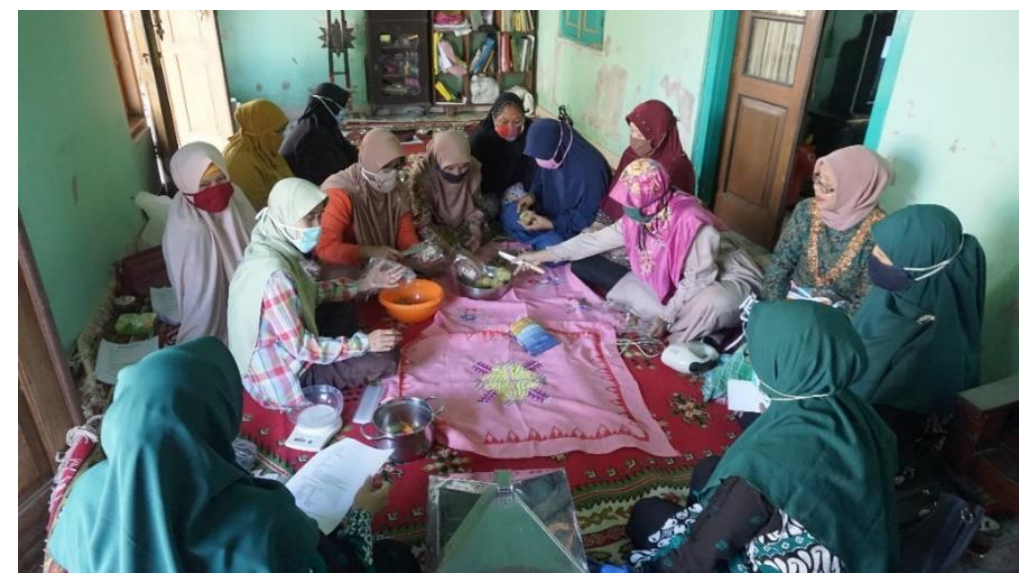

Gambar 1. Anggota Aisyiyah Ranting Tamantirto Utara praktik membuat kue dari bahan pangan lokal

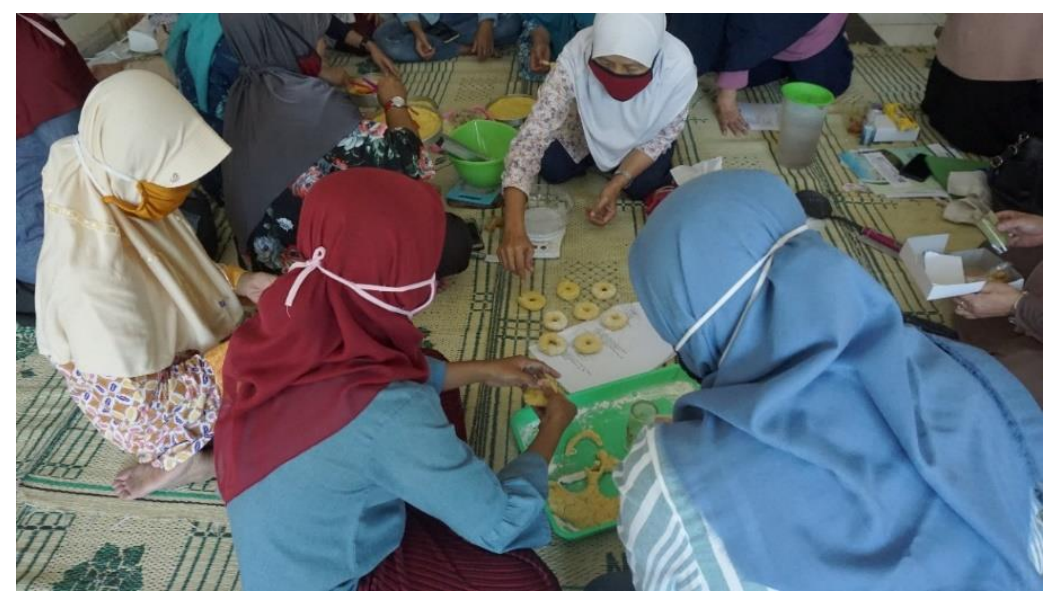

Gambar 2. Anggota Aisyiyah Ranting Ngestiharjo praktik membuat kue dari bahan pangan lokal

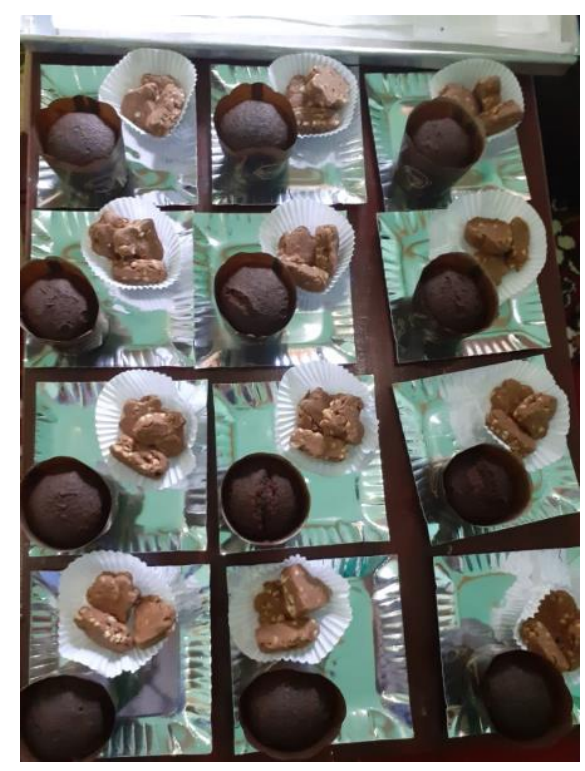

Gambar 3. Hasil praktik keu dari tepung mocaf berupa brownies dan cookies 


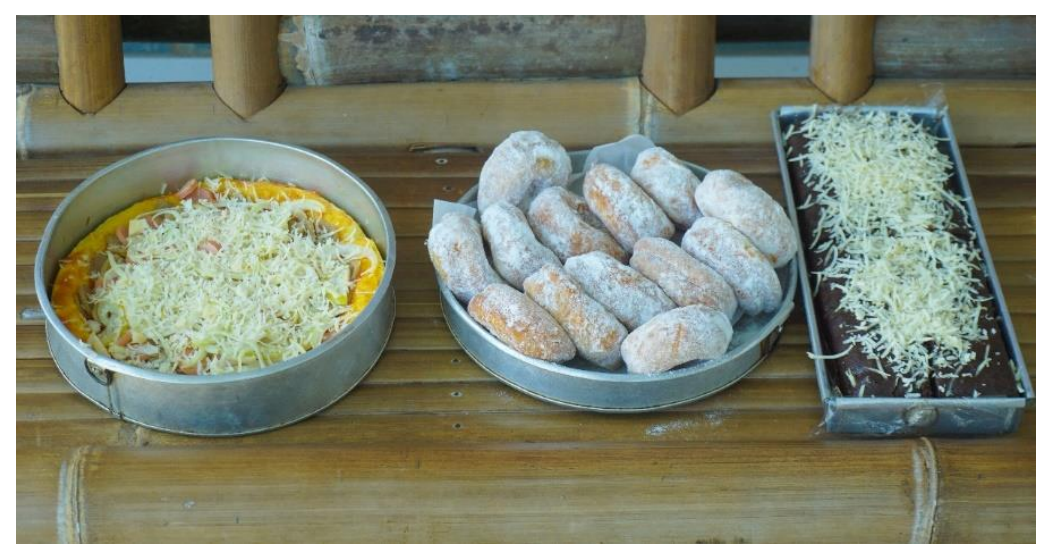

Gambar 4. Hasil praktik kue dari ubi jalar: brownies, pizza dan donat

\section{Penyuluhan Strategi Pemasaran}

Penyuluhan dan diskusi tentang strategi pemasaran dilakukan bersamaan dengan pelatihan pembuatan kue yaitu pada hari Minggu 15 Maret 2020 di Aisyiyah Ranting Tamantirto Utara dan tanggal Minggu 26 Juli 2020 tertempat di rumah anggota Aisyiyah kelompok Jomegatan Ranting Ngestiharjo. Tim abdimas menjelaskan strategi pemasaran berdasarkan konsep 4P (Kotler \& Amstrong, 2009; Dharmmesta \& Handoko, 2012) yang terdiri dari product (produk), price (harga), place (tepat) dan promotion (promosi). Peserta mengikuti penyuluhan dengan antusias dan menanyakan hal-hal yang belum jelas, sehingga diskusi dapat berlangsung dengan ramai dan hidup. Cara mengaplikasikan strategi pemasaran dengan konsep $4 \mathrm{P}$ yaitu:

a. Strategi Produk

Pelaku usaha harus membuat produk yang dapat diterima oleh masyarakat. Pengusaha dapat memulainya dengan cara mengembangkan produk yang dimiliki menjadi lebih baik. Kritik dan saran dari konsumen perlu ditampung sebagai bahan pertimbangan dan perbaikan. Menurut Kusumawaty (2018) strategi produk harus memperhatikan atribut produk, pemberian merek (branding), pengemasan, dan pemberian label (labelling). Kualitas produk yang baik tentu saja akan memberikan kepuasan yang tinggi dari konsumen. Sebaliknya, kualitas produk yang buruk akan membuat konsumen kecewa sehingga tidak mau membeli untuk kedua kalinya.

b. Strategi Harga

Harga merupakan salah satu hal yang sensitif dalam sebuah bisnis. Umumnya, konsumen akan menjadikan harga sebagai patokan untuk membandingkan dengan barang lain. Penting untuk menentukan harga yang tepat karena akan berpengaruh terhadap penjualan. Jangan sampai salah menentukan harga yang membuat konsumen menjadi tidak tertarik untuk membelinya. Penentuan harga dapat dengan cara melihat harga pasar atau menghitung HPP dan keuntungan yang diinginkan.

c. Strategi tempat

Tempat atau lokasi merupakan salah satu faktor penentu bisnis. Lokasi yang strategis merupakan lokasi yang ramai, dilalui oleh banyak orang, sehingga calon konsumen yang tertarik mudah untuk menemukan tempatnya.

d. Strategi Promosi

Promosi merupakan ujung tombak untuk memperkenalkan produk kepada masyarakat. Bentuk strategi promosi diantaranya: (1) Periklanan (melalui media televisi, radio, surat kabar, spanduk, brosur, kalender; (2) Promosi penjualan melalui kupon diskon/ undian pada momen tertentu, lomba, potongan harga; (3) Hubungan masyarakat 
dan publisitas (misalnya melalui seminar, lokakarya, workshop); (4) Penjualan personal misalnya sales promotion; (5) Pemasaran langsung, misalnya delivery order dan presentasi (Amanah, 2015).

Menurut Syukri, et al (2017) untuk meluaskan pasar, strategi yang diterapkan adalah: (1) Meluaskan jaringan melalui penggunaan media sosial (social media) seperti misalnya whatsup, facebook dan merespon dengan cepat setiap pesanan dari pelanggan online, (2) Meluaskan jaringan penjualan melalui toko oleh-oleh, (3) Mendesain ulang label pada kemasan agar lebih menarik dan menunjukkan ciri khas.

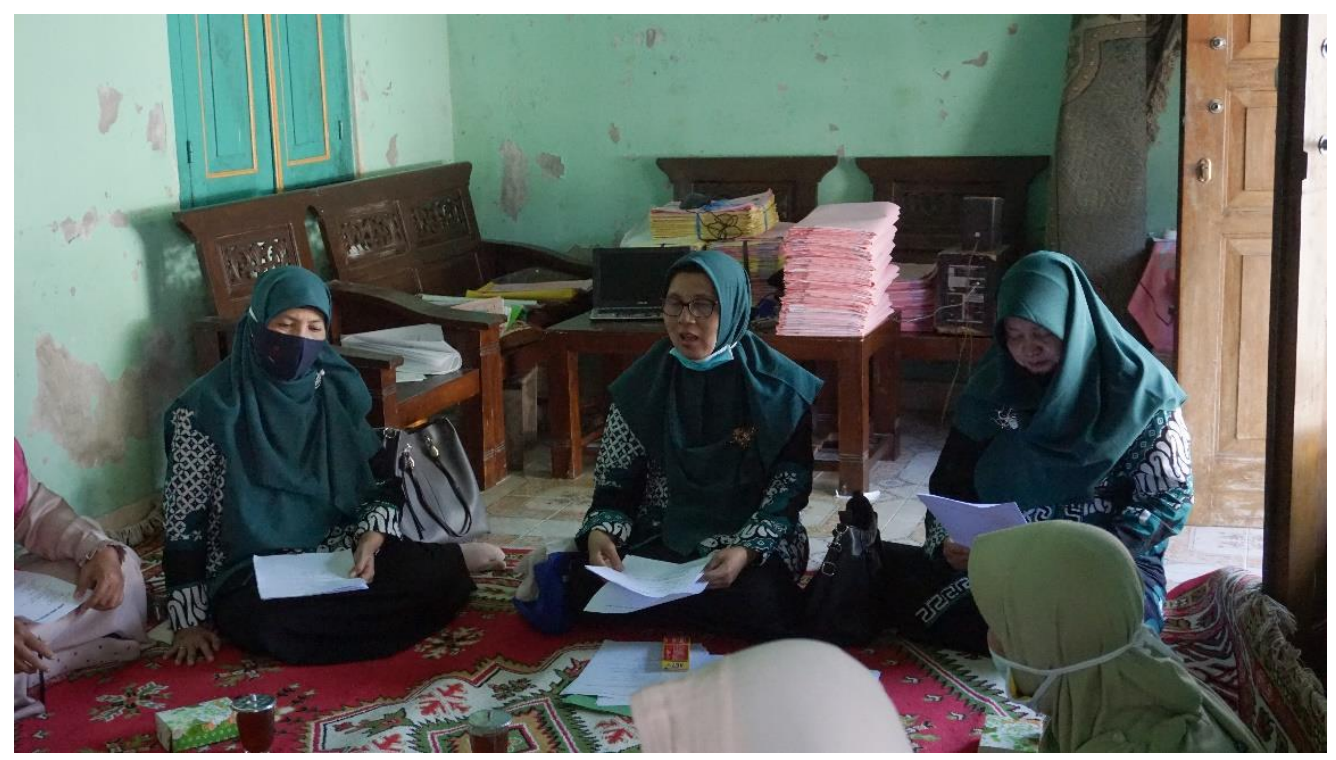

Gambar 7. Penyampaian materi strategi pemasaran oleh tim abdimas

3. Monitoring dan Evalusi Kegiatan

a. Evaluasi sebelum pelaksanaan kegiatan

Minat anggota Aisyiyah Ranting Tamantirto Utara dan Ngestiharjo untuk mengikuti pelatihan dan penyuluhan cukup tinggi dibuktikan dengan jumlah anggota yang hadir. Adanya pandemi covid 19 memang berpengaruh terhadap keikut sertaan anggota dalam kegiatan. Sekitar $80 \%$ anggota berpartisipasi aktif dalam kegiatan. Sebelum diadakan pelatihan dan penyuluhan diadakan pretest untuk mengetahui seberapa tingkat pengetahuan peserta terhadap berbagai hal yang terkait materi. Hasil pretest menunjukkan sebelum pelatihan tingkat pemahaman terhadap materi peserta sebesar $70,2 \%$

b. Evaluasi selama kegiatan berlangsung

Peserta yang mengikuti pelatihan, praktik dan penyuluhan mempunyai kemauan dan motivasi untuk mengimplementasikan. Hal ini dibuktikan dengan aktifnya para ibu-ibu mengikuti praktik membuat kue dari tepung mocaf dan ubi kayu. Ibu-ibu anggota Aisyiyah Ranting Tamantirto Utara dan Ngestiharjo dengan semangat mencoba sendiri setiap tahapan dalam pembuatan kue/roti.

c. Evaluasi setelah kegiatan selesai

Setelah pelaksanaan kegiatan juga dilakukan post test untuk mengetahui apakah ada tambahan pengetahuan dan pemahaman dalam pengolahan bahan pangan lokal dan strategi pemasaran. Hasil post test menunjukkan tingkat pemahaman peserta setelah mengikuti penyuluhan dan pelatihan meningkat dibandingkan sebelum kegiatan, dengan skor sebesar $88 \%$. Selain itu peserta yang mengikuti pelatihan dan penyuluhan juga 
sudah mulai membuat kue dari bahan pangan lokal untuk dijual, meskipun dibuat jika ada pesanan. Hal ini terjadi karena adanya pandemic covid 19 sehingga penjualan snack secara umum berkurang dibandingkan sebelumnya.

\section{Simpulan}

Pelaksanaan pemberdayaan anggota Aisyiyah Cabang Kasihan berbasis olahan bahan pangan lokal dilakukan melalui kegian pelatihan, praktik, fasilitasi peralatan untuk membuat kue dan penyuluhan tentang strategi pemasaran. Anggota Aisyiyah Ranting Tamantirto Utara dan Ngestiharjo antusias mengikuti kegiatan pelatihan dan praktik maupun penyuluhan. Berdasarkan hasil pretest dan posttest menunjukkan bahwa ada peningkatan pengetahuan sebelum dan sesudah adanya kegiatan pelatihan dan penyuluhan dari 70,2 \% menjadi $88 \%$. Adanya pandemik covid 19 menjadikan usaha pembuatan kue berbahan pangan lokal dibuat jika ada pesanan.

\section{Ucapan Terima Kasih}

Terima kasih penulis sampaikan ke LP3M Universitas Muhammadiyah Yogyakarta yang telah menfasilitasi dana untuk pelaksanaan pengabdian masyarakat. Ucapan terima kasih juga penulis sampaikan kepada ketua Aisyiyah Ranting Tamantirto Utara dan Kelompok Aisyiyah Jomegatan Ranting Ngestiharjo yang telah mengijinkan anggotanya untuk mengikuti kegiatan pemberdayaan masyarakat ini.

\section{Daftar Pustaka}

Amanah, S. 2015. Peranan Strategi Promosi Pemasaran Terhadap Peningkatan Volume Penjualan. Jurnal LENTERA 3(1): 47-55.

Astriani,D, Wafit,D \& Warmanti,M. 2011. Diversifikasi Pangan sebagai Solusi Mengatasi Rawan Pangan. Prosiding Seminar Nasional Revitalisasi Peran UMKM dalam Pembangunan melalui Penguatan Sektor Agroindustri. Program studi Agribisnis Fakultas Pertanian Universitas Sebelas Maret Surakarta.

Badan Pusat Statistik. 2017. Bantul Dalam Angka. Badan Pusat Statistik. Kabupaten Bantul.Yogyakarta

Bakti, A., Syarifah, \& Mutiara,E. 2017. Pengembangan Usaha Pengolahan Makanan Bahan Dasar Ubi di Desa Bingkat Kecamatan Pegajahan Kabupaten Serdang Bedagai. Jurnal Abdimas Talenta 2 (2) : 154-157

Ginting,E., Utomo,J.S., Yulifianti,R., \& Jusuf,M. 2011. Potensi Ubi Jalar Ungu sebagai Pangan Fungsional. Jurnal Iptek Tanaman Pangan 6(1): 116-138

Hastuti. 2016. Analisis Permintaan Import Gandum dan Tepung Terigu di Indonesia. Jurnal Bisnis Tani 2(2) : 171-181

Kusumawaty, Y. 2018. Strategi Pemasaran Produk Makanan Ringan Khas Riau (Keripik Nenas Dan Rengginang Ubi Kayu). Jurnal Agribisnis 20 (2) : 124-138

Kotler, P. \& Armstrong. 2009. Prinsip-Prinsip Pemasaran. Penerbit Erlangga, Jakarta.

Subagiyo, B.Setyono,B., Suparjana \& Hatmi,R.U. 2011. Prospek Pengembangan Agribisnis Tepung Mocaf di Tanjungsari Gunungkidul. Prosiding Seminar Hasil Penelitian Aneka Kacang dan Umbi. Balai Pengkajian Teknologi Pertanian Yogyakarta

Syukri,S.H.A., Rifa'i, A.F.\& Kurniawati, D.A. 2017. Pelatihan dan Pendampingan Produksi Makanan Berbasis Ikan Laut di Pulau Bawean. Jurnal Bakti Saintek 1(1): 27-34

Utami,P., \& Budinngsih,S. 2015. Potensi dan Ketersediaan Bahan Pangan Lokal Sumber Karbohidrat Non Beras di Kabupaten Banyumas. Jurnal Dinamika Ekonomi \& Bisnis 2(2) : 150-158 